\title{
Development of the Press-Through Package Recognizable with Abdominal X-Ray Image of Abdominal Soft Tissue Phantom
}

\author{
Kyoichi Ito ${ }^{1 *}$, Morio Shimada', Kiyomi Sadamoto3, Mikio Murata ${ }^{3}$, Kiyoshi Kubota4, \\ Motoyoshi Itoh", Kohki Yoshikawa² \\ ${ }^{1}$ Department of Radiation, International Goodwill Hospital, Yokohama, Japan \\ ${ }^{2}$ Department of Radiological Sciences, Faculty of Health Sciences, Komazawa University, Tokyo, Japan \\ ${ }^{3}$ Department of Clinical Pharmacy, Yokohama University of Pharmacy, Yokohama, Japan \\ ${ }^{4}$ Sanko Alumi Inc., Konosu, Saitama, Japan \\ Email: ^ito-k@shinzen.jp, mshimada@komazawa-u.ac.jp
}

How to cite this paper: Ito, K., Shimada, M., Sadamoto, K., Murata, M., Kubota, K., Itoh, M. and Yoshikawa, K. (2018) Development of the Press-Through Package Recognizable with Abdominal X-Ray Image of Abdominal Soft Tissue Phantom. Open Journal of Radiology, 8, 91-98.

https://doi.org/10.4236/ojrad.2018.82011

Received: May 27, 2018

Accepted: June 23, 2018

Published: June 26, 2018

Copyright $\odot 2018$ by authors and Scientific Research Publishing Inc. This work is licensed under the Creative Commons Attribution International License (CC BY 4.0).

http://creativecommons.org/licenses/by/4.0/

\begin{abstract}
Background: Patients with dementia who accidentally swallowed a pressthrough package (PTP) have been increased in recent years. Swallowed PTP is usually detected with CT having a risk of radiation exposure since PTP is very difficult to detect with abdominal X-ray image. Purpose: This study is aimed at developing the new PTP sheet recognizable with abdominal X-ray by improving the conventional PTP sheet. Material and Methods: The PTP sheet samples used in this study are: No. 1 Control: Commercially available tablet $100 \mathrm{mg}$, No. 2 Triple-stacked aluminum foil, 6-overcoated with $\mathrm{BaSO}_{4} 10.3$ $\mathrm{g} / \mathrm{m}^{2}$, No. 3 Aluminum foil, 6-overcoated with $\mathrm{BaSO}_{4} 10.3 \mathrm{~g} / \mathrm{m}^{2}$, No. 4 Five-stacked aluminum foil, 6-overcoated with $\mathrm{BaSO}_{4}$ No. 5 Aluminum foil, single-coated with $\mathrm{WO}_{3} 2.55 \mathrm{~g} / \mathrm{m}^{2}$, No. 6 Aluminum foil, double-coated with $\mathrm{WO}_{3} 5.1 \mathrm{~g} / \mathrm{m}^{2}$, No. 7 Aluminum foil, triple-coated with $\mathrm{WO}_{3} 7.66 \mathrm{~g} / \mathrm{m}^{2}$, No. 8 Three-stacked aluminum foil, triple-coated with $\mathrm{WO}_{3}$. PTP sheets (No. 1 No. 8) were placed inside the abdominal soft tissue phantom, and the images were obtained using FUJIFILM DR CALNEO PT. Region of interest (ROI) was placed on PTP sheets (No. 1 - No. 8) and abdominal soft tissue liquid phantom, and each contrast was measured from the average pixel of the two ROIs. Contrast was calculated by the calculation formula. Each ROI was measured three times, and their average value and standard deviation were estimated. Results: Statistical significance in contrast was not observed in commercial PTP sheet (No. 1), PTP sheet (No. 3), and PTP sheet (No. 5), while there was a significant difference between PTP sheet (No. 1) and PTP sheet (No. 2), PTP sheet (No. 4) PTP sheet (No. 6), PTP sheet (No. 7) $(\mathrm{p}<0.05)$. Significant difference in contrast was observed also between commercial PTP
\end{abstract}


sheet (No. 1) and PTP sheet (No. 8) (P < 0.01). PTP sheet (No. 1), PTP sheet (No. 3), and PTP sheet (No. 5) were not recognized at all by plain abdominal X-ray photography. Conclusion: The other all prototype PTP sheets (No. 2, No. 4, No. 6, No. 7 and No. 8) were well recognized. PTP sheets (No. 2, No. 4) of $\mathrm{BaSO}_{4}$ is considered to be more suitable than PTP sheets of $\mathrm{WO}_{3}$ (No. 6, No. 7, No. 8) because it is easier to produce. We will develop oral PTP sheets for patients with dementia for abdominal X-ray in the future.

\section{Keywords}

Press-Through Package (PTP), Soft Tissue Phantom, Abdominal X-Ray, Development, $\mathrm{BaSO}_{4}, \mathrm{WO}_{3}$

\section{Introduction}

Patients with dementia who accidentally swallowed a press-through package (PTP) have been increased in recent years. Swallowed PTP is usually detected with CT having a risk of radiation since PTP is very difficult to detect with abdominal X-ray image. PTP consists of lids coated with a heat-sealed material on an aluminum leaf and a dome of vinylchloride. These materials are widely used in Japan to enclose drugs due to their features of cleanliness, hermetic sealing, easy handling, toughness, and low cost. A risk of accidental swallow of PTP in the elderly individuals and the subjects with mental or visual disturbances is a serious issue for emergency physicians. Swallowed PTP with sharp corners may cause gastrointestinal bleeding, mediastinitis, intestinal perforation, and obstructive ileus, although such severe complications are extremely rare [1] [2] [3]. Endoscopic removal should be carried out if PTP exists in the esophagus or stomach. Early laparotomy should be considered if PTP passes through the pyloric ring and symptoms are observed [4]. Therefore, it is very important to make an early and correct diagnosis of the location of the PTP. PTP material is difficult to detect directly by plain radiography due to its high radiolucency, while there are increasing reports that the location of a PTP can be detected by multidetector computed tomography (MDCT) [4] [5] [6] [7] [8]. Therefore, we considered to make PTP sheet which can be recognized by plain X-ray examination with less exposure because CT examination receives much exposure.

\section{Purpose}

When we diagnose accidentally swallowing of patient's PTPs, we always use CT to diagnose that PTPs are in the stomach or intestinal tract. In these cases, CT scans give patients about 10 times more exposure than plain abdominal X-ray radiography.

Co-authors Sadamoto K, Murata M, Kubota K are specialists in pharmacy. They have been studying PTP safety and openness. On the other hand, Ito K, Shimada M, Yoshikawa $\mathrm{K}$ are experts in radiology. This project of development 
of this new PTP sheets were launched by a conference of these pharmaceutical experts and radiology experts together. As far as we search, there is no paper on the development of PTP sheets that can be recognized with Plain X-ray radiography.

The degree of X-ray detection is considered to be proportional to the fourth power of atomic number. From this, it turned out that barium and tungsten are the ones that can be painted as ink on the aluminum sheet of PTP.

This study is aimed at developing the new PTP sheet recognizable with plainabdominal X-ray by improving the conventional PTP sheet.

\section{Materials and Methods}

\subsection{Investigation of X-Ray Blocking Substances}

Compounds containing lead, barium, barium sulfate, titanium, iodine compounds, tin, lead, tungsten, bismuth, bismuth nitrite are considered as X-ray blocking substances. Barium sulfate, tungsten carbide, tin oxide, and bismuth oxide of a simple substance or compound having an atomic number of 47 or more are considered as candidates. X-ray detection sensitivity is proportional to the fourth power of atomic number. Candidates for X-ray blocking substances include iodine, barium, and tungsten. Bismuth is toxic and excluded. Iodine was excluded this time because atom number is smaller than barium. Barium and tungsten were finally selected as X-ray blocking substances. The ink containing blocking material (barium sulfate or tungsten trioxide) was coated on the cover material (aluminum foil) of PTP sheet in the form of gravure print.

\subsection{Method of Overcoating with a Coater}

Possibility of industrialization (commercialization) by gravure ink

Atomic ratio of tungsten carbide [WC] W $=183.8 / 195.851$

Compared with this, the atomic ratio of barium sulfate $\mathrm{Ba}=137.3 / 233.43$

$\mathrm{X}$-ray shielding effect $\mathrm{W}: \mathrm{Ba}=29.99: 9.83$

$50 \mathrm{~g} / \mathrm{m}^{2} \mathrm{BaSO}_{4}$ (Solid) $\rightarrow$ WC $50 \times 0.328 \times(1.066 / 1.700)=10.283 \mathrm{~g} / \mathrm{m}^{2}$

The present prototype PTP aluminum was tungsten trioxide

$\mathrm{WO}_{3}=231.84$ atomic ratio of tungsten $\mathrm{W}=183.8 / 231.84=0.7928$

Therefore, neodarum sol ( $\mathrm{BaSO}_{4}$ : Kaigen Pharma CO., LTD. Tokyo Japan) solution 2 -fold dilution $\rightarrow$ " $\mathrm{WO}_{3}=12.093 \mathrm{~g} / \mathrm{m}^{2}$

We prepared prototype PTP sheets using the inks of barium sulfate and tungsten trioxide ink. Commercially available medicinal zyrolic tablets (hyperuricemia drug: Daiichi Sankyo Company, Limited. Tokyo Japan).

Japan) were used as a control.

PTP sheet samples are No. 1 to No. 8 below (Figure 1).

No. 1: Control: commercially available zyrolic tablet $100 \mathrm{mg}$ PTP

No. 2: Triple-stacked aluminum foil, 6-overcoated with $\mathrm{BaSO}_{4} 10.3 \mathrm{~g} / \mathrm{m}^{2}$ (solid $\left.15.0 \mathrm{~g} / \mathrm{m}^{2}\right)$

No. 3: Aluminum foil, 6-overcoated with $\mathrm{BaSO}_{4} 10.3 \mathrm{~g} / \mathrm{m}^{2}$ (solid $15.0 \mathrm{~g} / \mathrm{m}^{2}$ ) 


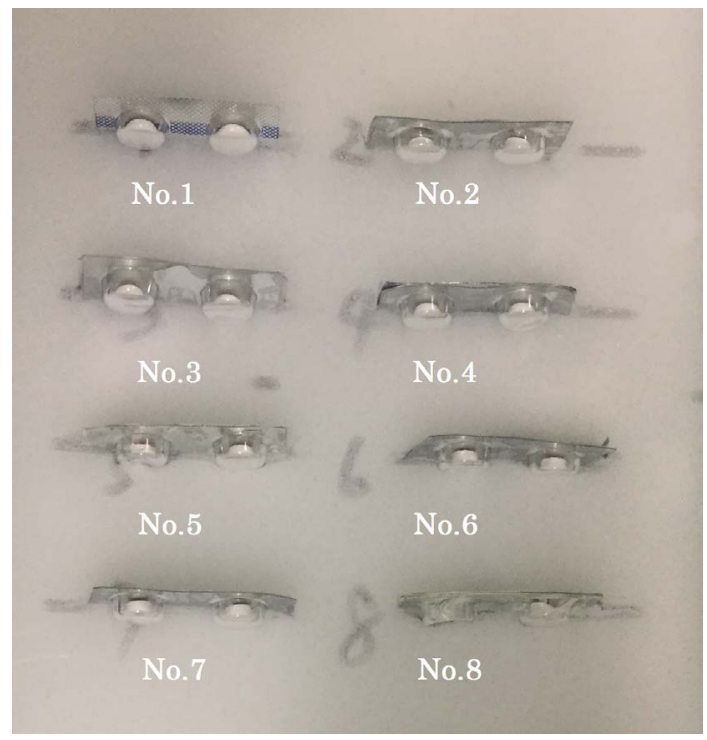

Figure 1. Samples of PTP sheets (No. 1 - No. 8).

No. 4: Five-stacked aluminum foil, 6-overcoated with $\mathrm{BaSO}_{4}$

No. 5: Aluminum foil, single-coated with $\mathrm{WO}_{3} 2.55 \mathrm{~g} / \mathrm{m}^{2}$ (solid $3.5 \mathrm{~g} / \mathrm{m}^{2}$ )

No. 6: Aluminum foil, double-coated with $\mathrm{WO}_{3} 5.1 \mathrm{~g} / \mathrm{m}^{2}$

No. 7: Aluminum foil, triple-coated with $\mathrm{WO}_{3} 7.66 \mathrm{~g} / \mathrm{m}^{2}$

No. 8: Three-stacked aluminum foil, triple-coated with $\mathrm{WO}_{3}$

\subsection{Method of Preparation of Abdominal Soft Tissue Phantom}

A polyethylene container was used for preparation of a soft tissue equivalent phantom. The size of the container is $320 \mathrm{~mm}$ (sideway) $\times 170 \mathrm{~mm}$ (height) $\times$ $160 \mathrm{~mm}$ (length), and the volume is $8704 \mathrm{ml}$. In this volume $6144 \mathrm{ml}, 1081 \mathrm{~g}$ of granulated sugar and $79.87 \mathrm{~g}$ of salt were added at a ratio of granulated sugar 176 $\mathrm{mg} / \mathrm{mL}$ water vs salt $13 \mathrm{mg} / \mathrm{mL}$ water to prepare an abdominal soft tissue phantom. Two melamine foams in a size of $30 \mathrm{~mm}$ (height) $\times 300 \mathrm{~mm}$ (width) $\times 135$ $\mathrm{mm}$ (length) were overpositioned, slits were made, and PTP sheets (No. 1 - No. 8) were inserted through these slits avoiding their floating (Figure 2).

\subsection{Measurement Method of Contrast of PTP Sheets}

PTP sheets (No. 1 - No. 8) were placed inside the abdominal soft tissue phantom, and the images were obtained at the specified condition of voltage $76 \mathrm{Kv}$, electric current $200 \mathrm{~mA}$, time $160 \mathrm{msec}$, using FUJIFILM DR CALNEO PT (Fujifilm Corporation Tokyo Japan). Region of interest (ROI) was placed on PTP sheets (No. 1 - No. 8) and abdominal soft tissue liquid phantom, and each contrast was measured from the average pixel of the two ROIs. Contrast was calculated by the calculation formula below.

Contrast $=($ ROIptp - ROIphantom $) /$ ROIphantom

Each ROI was measured three times, and their average value and standard deviation were estimated. 


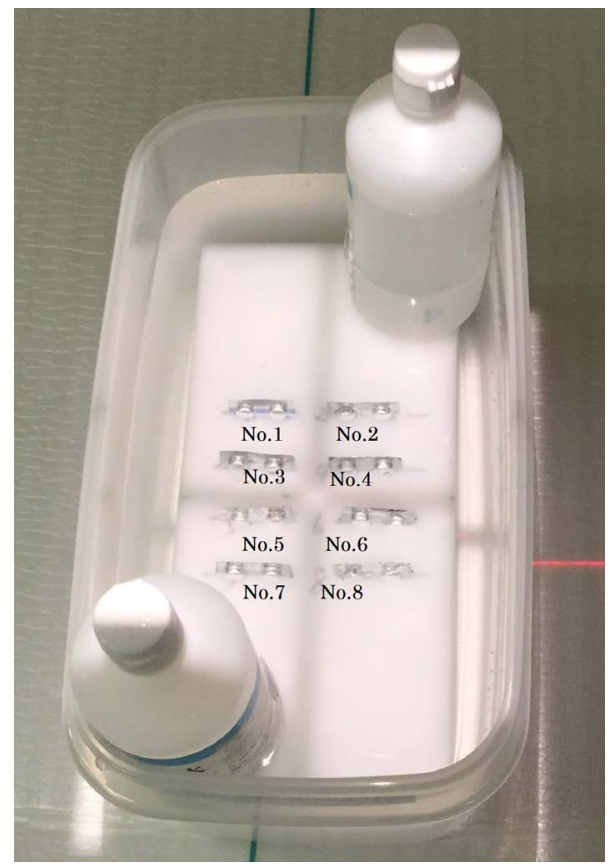

Figure 2. Abdominal soft tissue phantom with PTP sheets (No. 1 - No. 8). Above and below bottles containing water are the weights not to float melamine foam.

\subsection{Statistical Analysis}

Differences in Contrast between the commercial PTP and our prototype PTPs were compared using an unpaired t-test. The P-value was assessed. All statistical analyses were performed with Excel Statistics 2010 for Windows version 1.13.

\section{Results}

PTP of No. 1 (Control: commercially available zyrolic tablet) was hardly detected.

Contrast of PTP (No. 1) was as low as 0.01501.

PTP of No. 2 (Triple-stacked aluminum foil, 6-overcoated with $\mathrm{BaSO}_{4}$ ) was moderately recognized. Contrast of PTP (No. 2) was a moderate value of 0.1146 . PTP of No. 3 (Aluminum foil, 6-overcoated with $\mathrm{BaSO}_{4}$ ) was hardly detected as same as PTP (No. 1). Contrast of PTP (No. 3) was as low as 0.03729. PTP of No. 4 (Five-stacked aluminum foil, 6-overcoated with $\mathrm{BaSO}_{4}$ ) was clearly detected. Contrast of PTP (No. 4) was relatively higher as 0.1694 . PTP of No. 5 (Aluminum foil, single-coated with $\mathrm{WO}_{3}$ ) was hardly detected as same as PTP (No. 1). Contrast of PTP (No. 5) was as low as 0.03223 . PTP of No. 6 (Aluminum foil, double-coated with $\mathrm{WO}_{3}$ ) was able to be recognized moderately. Contrast of PTP (No. 6) was a moderate value of 0.1331. PTP of No. 7 (Aluminum foil, triple-coated with $\mathrm{WO}_{3}$ ) was clearly detected. Contrast of PTP (No. 7) was relatively higher as 0.1832 . PTP of No. 8 (Three-stacked aluminum foil, triple-coated with $\mathrm{WO}_{3}$ ) was clearly detected. Contrast of PTP (No. 8) was 0.2173 and highest 
among all. There were no significant differences in contrast among commercially available PTP (No. 1), PTP (No. 3) and PTP (No. 5). However there was a significant difference between PTP sheet (No. 1) and PTP sheet (No. 2), PTP sheet (No. 4) PTP sheet (No. 6), PTP sheet (No. 7) $(\mathrm{p}<0.05)$. Significant differences in contrast were observed also between commercially available PTP (No. 1) and PTP (No. 8) $(\mathrm{P}<0.01)$ (Figure 3) (Figure 4).

\section{Discussion}

MDCT was performed using a 64-detector-row system (CT LightSpeed VCT; GEHealthcare, Milwaukee, USA). Imaging and reconstructionparameters for the 40 -section device were a beamcollimation of $8 \times 2.5 \mathrm{~mm}$, a beam pitch of 1.35 , a gantryrotation time of $0.6 \mathrm{~s}, 120 \mathrm{kVp}, 199 \mathrm{mAs}$, a section thicknessof $1.25 \mathrm{~mm}$ and a reconstruction interval of $1.25 \mathrm{~mm}$ using same PTP sheets (No. 1 - No. 8) (Figure 5).

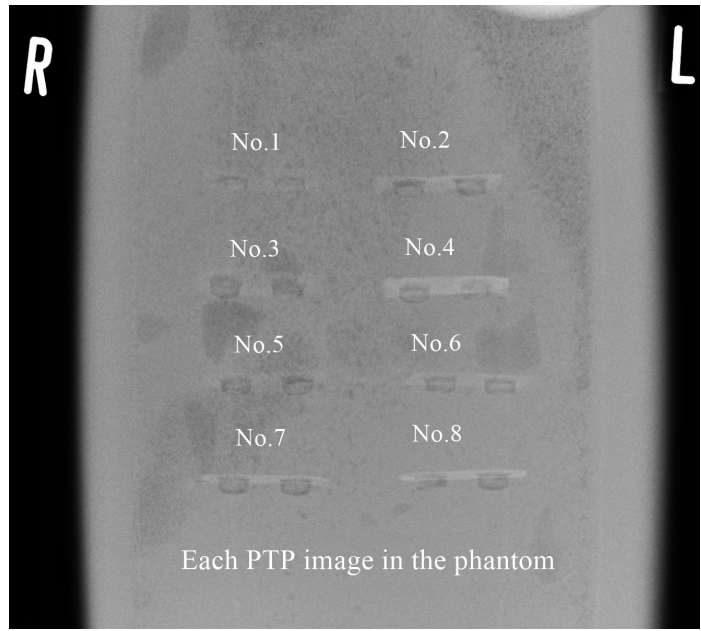

Figure 3. Abdominal X-ray image of each PTP sheets in the phantom.

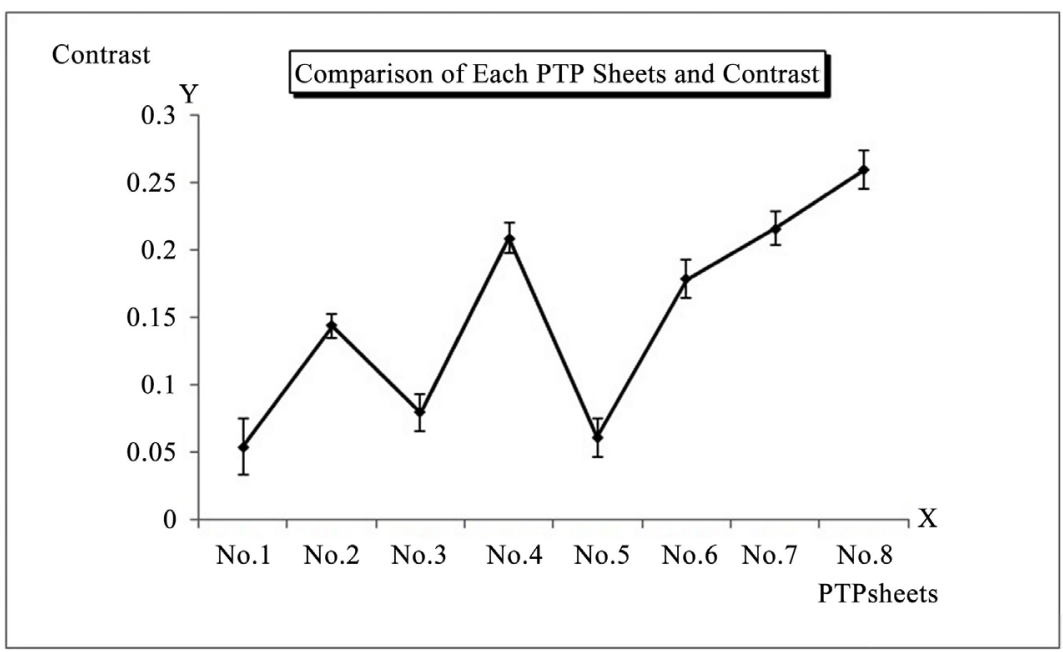

Figure 4. Comparison of each PTP sheets and contrast. 


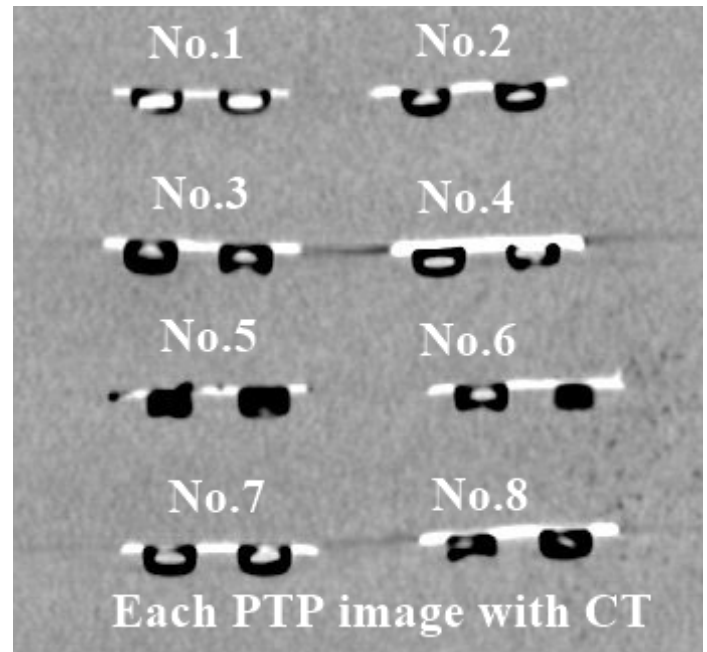

Figure 5. CT coronal reconstraction image of PTP sheets (No. 1 - No. 8).

All PTP sheets (No. 1 - No. 8) depict very clearly by CT scan. We always use CT to diagnose that PTPs are in the stomach or intestinal tract. In these cases, CT scans give patients about 10 times more exposure than plain abdominal $\mathrm{X}$-ray radiography.

Inadvertent PTP ingestion is being diagnosed more frequently in cases of foreign bodies in the digestive tract [7] [8].

Radiological tests play a very important role in revealing the location of PTPs that have been inadvertently swallowed. However, contrary to popular opinion, preoperative confirmation of PTPs in the UGI tract is difficult due to their radiolucency.

Elderly patients often visit the emergency hospital for increasing of the associated proportion of the population with dementia, the increased number of drugs dispensed in PTPs, and a lack of attention. Commercially available PTP sheets are unable to recognize in plain radiographs. For this reason, CT scanning is a common practice to examine presence or absence of PTP sheets for the patients who doubted accidental swallow of PTP sheets. We prepared PTP sheets of new materials (barium sulfate and tungsten trioxide). In these PTP sheets, the ink containing blocking material of barium sulfate or tungsten trioxide was overcoated in the form of gravure print on the aluminum foil of lid material of the PTP sheet. As far as we know, it was simply described in Japanese patent files that barium sulfate is used in the applied product. There are no literatures related to PTP sheets of barium sulfate or tungsten trioxide. The results showed that PTP sheet can be recognized with plain X-ray of less exposure dose if it has at least the same or more potent contrast with PTP (No. 2). Since barium is kneaded in the coating ink, this product can be commercialized without difficulty. We showed that the PTPs of No. 6 and more containing tungsten are recognizable with plain X-ray. However, commercialization is now found to be difficult since kneading of tungsten in the coating ink at commercial base is 
practically difficult.

\section{Conclusions}

PTP (No. 1), PTP (No. 3), and PTP (No. 5) were not recognized at all by simple $\mathrm{X}$-ray photography. At the present time, $\mathrm{BaSO}_{4} \mathrm{PTP}$ sheet above the concentration of PTP sheet (No. 2) (Triple-stacked aluminum foil, 6-overcoated with Ba$\left.\mathrm{SO}_{4} 10.3 \mathrm{~g} / \mathrm{m}^{2}\right)$ is considered most suitable.

The other all prototype press-through packages (No. 2, No. 4, No. 6, No. 7, No. 8) were well recognized. From now on, we will further improve these PTP sheets recognizable by plain X-ray and develop PTP sheet that can be orally administered to patients.

There were no significant differences in contrast among commercially available PTP (No. 1), PTP (No. 3) and PTP (No. 5). There was a significant difference between PTP (No. 1) and PTP (No. 2), PTP (No. 4) PTP (No. 6), PTP (No. 7) (p $<0.05)$. Significant difference in contrast was observed also between commercial PTP (No. 1) and PTP (No. 8) $(\mathrm{P}<0.01)$.

All PTP sheets (No. 1 - No. 8) depict very clearly by CT scan.

\section{References}

[1] Norstein, J., Krajci, P., Bergan, A. and Geiran, O. (1995) Intestinal Perforation after Igestion of a Blister-Wrapped Tablet. Lancet, 346, 1308. https://doi.org/10.1016/S0140-6736(95)91918-X

[2] Imaizumi, H., Yamauchi, M., Namiki, A., Takahashi, H. and Hatakeyama, K. (1997) Obstructive Ileus Caused by a Swallowed Foreign Body (a "Press-Through" Package) and Preexisting Adhesions. American Journal of Emergency Medicine, 15, 52-53. https://doi.org/10.1016/S0735-6757(97)90048-6

[3] Sudo, T., Sueyoshi, S., Fujita, H., Yamana, H. and Shirouzu, K. (2003) Esophageal Perforation Caused by a Press through Pack. Diseases of the Esophagus, 16, 169-172. https://doi.org/10.1046/j.1442-2050.2003.00320.x

[4] Domen, H., Ohara, M., Noguchi, M., et al. (2011) Inadvertent Ingestion of a Press-Through Package Causing Perforation of the Small Intestine within an Incisional Hernia and Panperitonitis. Case Reports in Gastroenterology, 5, 391-395. https://doi.org/10.1159/000330290

[5] Hou, S.K., Chern, C.H., How, C.K., Wang, L.M., Huang, C.I. and Lee, C.H. (2006) Press through Pack-Age Miss-Swallowing. International Journal of Clinical Practice, 60, 234-237. https://doi.org/10.1111/j.1742-1241.2006.00766.x

[6] Bosmans, J.M., Spinhoven, M.J., Deckers, F.P., Pouillon, M.M., Borre, F.J. and Parizel, P.M. (2006) Ac Cidental Ingestion of a Press-Through Package: An underestimated Cause of Serious Iatrogenic Disease in the Elderly? Journal of the American Geriatrics Society, 54, 1467-1468. https://doi.org/10.1111/j.1532-5415.2006.00858.x

[7] Takada, M., Kashiwagi, R., Sakane, M., Tabata, F. and Kuroda, Y. (2000) 3D-CT Diagnosis for Ingested Foreign Bodies. American Journal of Emergency Medicine, 18, 192-193. https://doi.org/10.1016/S0735-6757(00)90018-4

[8] Yamaguchi, H., Yamashita, H., Yamauchi, H., Suzuki, T., Ishimaru, M. and Nagawa, H. (2005) Intestinal Perforation Caused by Stagnated Press-Though Packages. Surgery, 137, 661-662. https://doi.org/10.1016/j.surg.2004.01.016 